\title{
Role of in-situ formed free carbon on electromagnetic absorption properties of polymer-derived SiC ceramics
}

\author{
Zhaoju YU ${ }^{a, b, *}$, Xuan $\mathrm{LV}^{a}$, Kangwei MAO ${ }^{a}$, Yujing YANG ${ }^{a}$, Anhua LIU ${ }^{a, b, c, *}$ \\ ${ }^{a}$ College of Materials, Key Laboratory of High Performance Ceramic Fibers (Xiamen University), \\ Ministry of Education, Xiamen 361005, China \\ ${ }^{b}$ College of Materials, Fujian Key Laboratory of Advanced Materials (Xiamen University), Xiamen 361005, China \\ 'Shenzhen Research Institute of Xiamen University, Shenzhen 518000, China
}

Received: February 25, 2020; Revised: June 28, 2020; Accepted: June 30, 2020

(C) The Author(s) 2020.

\begin{abstract}
In order to enhance dielectric properties of polymer-derived $\mathrm{SiC}$ ceramics, a novel single-source-precursor was synthesized by the reaction of an allylhydrido polycarbosilane (AHPCS) and divinyl benzene (DVB) to form carbon-rich SiC. As expected, the free carbon contents of resultant $\mathrm{SiC}$ ceramics annealed at $1600{ }^{\circ} \mathrm{C}$ are significantly enhanced from $6.62 \mathrm{wt} \%$ to $44.67 \mathrm{wt} \%$. After annealing at $900-1600{ }^{\circ} \mathrm{C}$, the obtained carbon-rich $\mathrm{SiC}$ ceramics undergo phase separation from amorphous to crystalline feature where superfine $\mathrm{SiC}$ nanocrystals and turbostratic carbon networks are dispersed in an amorphous $\mathrm{SiC}(\mathrm{O})$ matrix. The dielectric properties and electromagnetic (EM) absorption performance of as-synthesized carbon-rich $\mathrm{SiC}$ ceramics are significantly improved by increasing the structural order and content of free carbon. For the $1600{ }^{\circ} \mathrm{C}$ ceramics mixed with paraffin wax, the minimum reflection coefficient $\left(R C_{\min }\right)$ reaches $-56.8 \mathrm{~dB}$ at $15.2 \mathrm{GHz}$ with the thickness of $1.51 \mathrm{~mm}$ and a relatively broad effective bandwidth (the bandwidth of $R C$ values lower than $-10 \mathrm{~dB}$ ) of $4.43 \mathrm{GHz}$, indicating the excellent EM absorption performance. The carbon-rich $\mathrm{SiC}$ ceramics have to be considered as harsh environmental EM absorbers with excellent chemical stability, high temperature, and oxidation and corrosion resistance.
\end{abstract}

Keywords: polymer-derived ceramics (PDCs); microstructural evolution; dielectric properties; electromagnetic properties

\section{Introduction}

Centimeter-wave frequency electromagnetic (EM) waves $(2-18 \mathrm{GHz})$ are widely used in various environments, which require high efficient EM absorbing (EMA) materials due to the massive increasing use of high

* Corresponding authors.

E-mail: Z.Yu, zhaojuyu@xmu.edu.cn;

A. Liu, ahliu@xmu.edu.cn operating frequencies and bandwidths in electronic systems [1-7]. Recently, polymer-derived ceramics (PDCs) attract great attention as EM absorbers since they possess tunable dielectric properties and conductivities, low density, excellent high-temperature mechanical properties, oxidation, and corrosion resistance as well as thermophysical and chemical stabilities $[8,9]$. However, due to their intrinsic low permittivity, high-temperature resistant ceramics including most PDCs in general cannot meet the basic requirements for the application as EMA materials [8]. 
Pristine PDCs without additional conductive fillers mostly show low dielectric loss [9-17]. Due to the excellent electrical conductivity of carbon nanophasebased families, such as carbon nanotubes, graphene, and reduced graphene oxide, great efforts have therefore been made to introduce them into the PDCs to enhance the EMA performance [18-26]. However, as an EM absorbent, the effective utilization of carbon nanophase in composites depends strongly on their dispersed state since the agglomeration can lead to an inferior polarization relaxation and electrical conductivity [21]. Therefore, complicated chemistry is always involved to homogeneously distribute the carbon nanophase in the matrix $[22,23,26]$. It is worth pointing out that a phenomenon associated with the PDC, namely, the in-situ formation of free carbon within the generated silicon-based ceramic matrix has been widely reported [27-30]. Among the phases occurring in the PDCs, most of them are insulators (e.g., $\mathrm{SiO}_{2}$ and $\mathrm{Si}_{3} \mathrm{~N}_{4}$ ) or semiconductors $\left(\mathrm{SiC}, \mathrm{SiO}_{x} \mathrm{C}_{y}, \mathrm{SiC}_{x} \mathrm{~N}_{y}\right.$, and amorphous carbon) with the room-temperature DC electrical conductivity in the ranges of $10^{-14}-10^{-12} \mathrm{~S} / \mathrm{cm}$ for insulators and $10^{-4}-10^{2} \mathrm{~S} / \mathrm{cm}$ for semiconductors [30]. Only the segregated free carbon which exists in the form of turbostratic carbon or graphitic carbon within the PDCs has a significantly higher electrical conductivity in the range of $1-10^{5} \mathrm{~S} / \mathrm{cm}$ [31]. Compared with the incorporated carbon nanophase, the free carbon is in-situ formed and homogeneously distributed with the PDC-based ceramic matrix to avoid the agglomeration, which facilitates the resultant dielectric and EM absorbing properties. Therefore, the in-situ generated carbon within the PDC matrix has been considered as conductive phase and plays a critical role to improve the final EM absorbing properties [32-41].

Among the above-mentioned studies, metal-based compounds are often involved in the complicated composites and influence the final EM properties, which makes it difficult to evaluate the contribution of in-situ formed free carbon $[33,38,40,41]$. Therefore, the effect of in-situ formed carbon including the concentration and/or structural evolution on the dielectric properties and EM absorbing performance of the PDCs has never been systematically discussed up to now. To keep this consideration in mind, we tried to synthesize metal-free and carbon-rich $\mathrm{SiC}$ with tunable free carbon contents. The amount and morphology of free carbon within the PDCs strongly depend on the molecular structure of preceramic polymers and the nature of organic substituents [42]. Divinyl benzene (DVB) is rich in unsaturated groups $(\mathrm{C}=\mathrm{C}$ and phenyl), which is often used as an additional carbon source to enhance the carbon content in final PDCs $[43,44]$. Therefore, in the present study, DVB was introduced into an allylhydrido polycarbosilane (AHPCS) to form a carbon-rich single-source-precursor. The free carbon content of resulting ceramics can be easily tuned by the amount of DVB in the feed. The dielectric properties and EM absorption performance of as-synthesized carbon-rich $\mathrm{SiC}$ ceramics mixed with a paraffin wax matrix were systematically investigated. A relationship between the content/microstructure of in-situ formed free carbon and dielectric/EM properties of the resultant carbon-rich $\mathrm{SiC}$ ceramics will be acquired.

\section{Experimental}

\section{1 Materials}

The AHPCS with a formal composition $\left[\mathrm{SiH}_{1.26}\left(\mathrm{CH}_{3}\right)_{0.60}\right.$ $\left.\left(\mathrm{CH}_{2} \mathrm{CH}=\mathrm{CH}_{2}\right)_{0.14} \mathrm{CH}_{2}\right]_{n}$ was synthesized as previously reported [45]. DVB was purchased from Aldrich. Paraffin wax (Ar) was bought from Shanghai Hualing Health Machinery Co., China. The Ar atmosphere was used for pyrolysis and annealing process with a purity of $99.99 \%$. Other commercially available reagents were used as received.

\section{2 Synthesis of single-source-precursors}

One typical synthesis of single-source-precursor was achieved as follows: Firstly, $3.000 \mathrm{~g}$ AHPCS and $3.000 \mathrm{~g}$ DVB were added to the Schlenk flask equipped with a gas inlet, reflux condenser, and a gas outlet. The obtained yellow solution was then heated up to $160{ }^{\circ} \mathrm{C}$ in an oil bath for $6 \mathrm{~h}$ in the Ar atmosphere with magnetic stirring. Finally, a pale yellow solid can be obtained and denoted as PAD-2. A series of single-source-precursor PADs with different DVB contents in the feed were prepared (Table 1). To make a comparison, a control test was performed under the same conditions but no

Table 1 Content of AHPCS and DVB in the feed

\begin{tabular}{ccc}
\hline Precursor & AHPCS (wt\%) & DVB (wt\%) \\
\hline AHPCS-blank & 100 & 0 \\
PAD-1 & 67 & 33 \\
PAD-2 & 50 & 50 \\
PAD-3 & 40 & 60 \\
\hline
\end{tabular}


DVB was added, and the resultant product is nominated as AHPCS-blank.

\section{3 Polymer-to-ceramic transformation}

The single-source-precursors were pyrolyzed in the Ar atmosphere as follows: heating up to the target temperature $\left(300,600\right.$, or $900{ }^{\circ} \mathrm{C}$ ) hold for $2 \mathrm{~h}$ and followed by cooling down to room temperature. The typical heating rate is as follows: $20-500{ }^{\circ} \mathrm{C}, 2{ }^{\circ} \mathrm{C} / \mathrm{min}$; 500-900 ${ }^{\circ} \mathrm{C}, 5{ }^{\circ} \mathrm{C} / \mathrm{min}$. Finally, the amorphous ceramic (pre-pyrolyzed at $900{ }^{\circ} \mathrm{C}$ ) was annealed at different temperatures in the range of $1200-1600{ }^{\circ} \mathrm{C}$. The $900{ }^{\circ} \mathrm{C}$ ceramic was transferred to a graphite crucible in a tube furnace and then heated rapidly in $\mathrm{Ar}$ to a target temperature at a rate of $5{ }^{\circ} \mathrm{C} / \mathrm{min}$ and kept at this temperature for $2 \mathrm{~h}$. After annealing, the resulting ceramic was furnace-cooled to room temperature. The synthesis procedure from precursors to ceramic powders is illustrated in Fig. 1.

\section{4 Characterization}

Fourier transform infrared spectroscopy (FT-IR) was recorded on a Nicolet Avator 360 apparatus (Nicolet, Madison, WI) in the range of 4000-500 $\mathrm{cm}^{-1}$ with $\mathrm{KBr}$ plates for liquid samples and $\mathrm{KBr}$ disks for solid samples. Elemental analysis of the ceramic powders was carried out by Horiba Carbon/Sulfur Analyzer EMIA-320V (Horiba, Kyoto, Japan) for carbon element, Horiba Oxygen/Nitrogen Analyzer EMGA-620W (Horiba) for oxygen element, and Elemental Analyzer EA/MA1110 (Carlo Erba, Italy) for hydrogen element. The Si fraction was calculated as the difference between $100 \%$ and the values of the other elements. Raman spectra were recorded from 100 to $4000 \mathrm{~cm}^{-1}$ employing a microRaman spectrometer (XploRA, HORIBA Scientific) using a laser wavelength of $532 \mathrm{~nm}$. Transmission electron microscope (TEM, JEM-2100, JEOL, Tokyo, Japan) was used to observe the microstructure of the ceramics annealed at different temperatures, and the TEM specimens were prepared by mechanical grinding.
The electromagnetic parameters of the ceramics have been determined by the coaxial transmission/reflection method in 2-18 GHz. The ceramic powders were homogeneously mixed with molten paraffin (weight ratio ceramic/paraffin wax of 4:6) and pressed into hollow cylinder-shaped samples (inner diameter: $3.04 \mathrm{~mm}$; external diameter: $7.00 \mathrm{~mm}$; height: $3.04 \mathrm{~mm}$ ). The complex permittivity of the samples was calculated from the scattering parameters (S-parameters) corresponding to transmission $\left(\mathrm{S}_{21}\right.$ and $\left.\mathrm{S}_{12}\right)$ and reflection $\left(\mathrm{S}_{11}\right.$ and $\mathrm{S}_{22}$ ) measured on an N5222A PNA-X Vector Network Analyzer (10 MHz to $26.5 \mathrm{GHz}$, Agilent Technologies Inc., Santa Clara, CA). The hollow cylinder-shaped samples were tightly fixed into the $50 \Omega$ Airline (85051-60007, Agilent) and the measurements were calibrated using an electronic calibration module (N4696-60004, 300 kHz-18 GHz, Agilent).

\section{Results and discussion}

\section{1 Characterization of single-source-precursors}

To trace the molecular structure evolution during the single-source-precursor synthesis, the FT-IR spectra of the original AHPCS, DVB, unreacted AHPCS/DVB mixture, and obtained PAD-2 (taking the PAD-2 as an example) were measured, and the results are shown in Fig. 2.

The major absorption bands of DVB were observed at $3088 \mathrm{~cm}^{-1}$ due to $\mathrm{C}-\mathrm{H}$ stretch in $-\mathrm{CH}=\mathrm{CH}_{2}$ and at $1630 \mathrm{~cm}^{-1}$ due to $\mathrm{C}=\mathrm{C}$ stretch in $-\mathrm{CH}=\mathrm{CH}_{2}$. The broadband centered at $3025 \mathrm{~cm}^{-1}$ is due to phenyl $\mathrm{C}-\mathrm{H}$ stretching. Other major bonds in the DVB include phenyl C-C (1594, $\left.1574 \mathrm{~cm}^{-1}\right)$, phenyl C-H $\left(1510 \mathrm{~cm}^{-1}\right)$, and phenyl $\mathrm{C}-\mathrm{C}$ out-of-plane bending $\left(900-650 \mathrm{~cm}^{-1}\right)$ can be assigned [46,47]. According to our previous study [45], the typical AHPCS characteristic peaks are marked in Fig. 2(b). It is worth mentioning that the $\mathrm{C}-\mathrm{H}$ stretch in $\mathrm{C}=\mathrm{C}-\mathrm{H}$ groups $\left(3077 \mathrm{~cm}^{-1}\right)$ and $\mathrm{C}=\mathrm{C}$ stretch $\left(1630 \mathrm{~cm}^{-1}\right)$ peaks significantly decrease after the reaction, evidencing the structural differences between

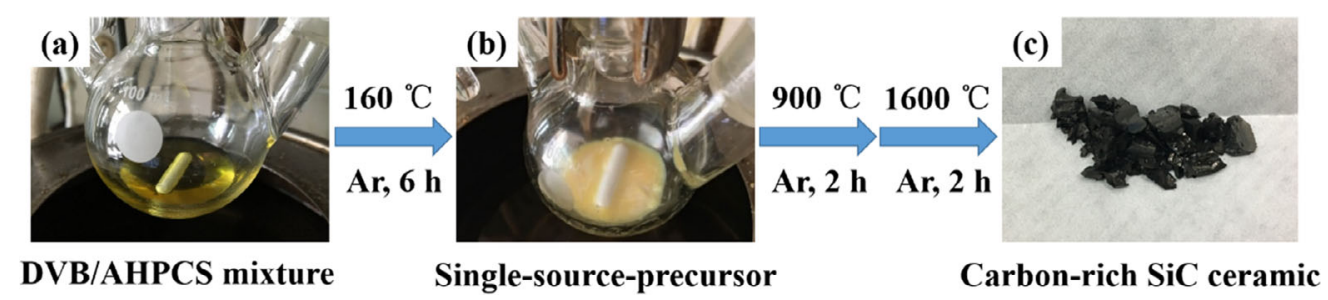

Fig. 1 Photographic illustration of the synthesis procedure. 

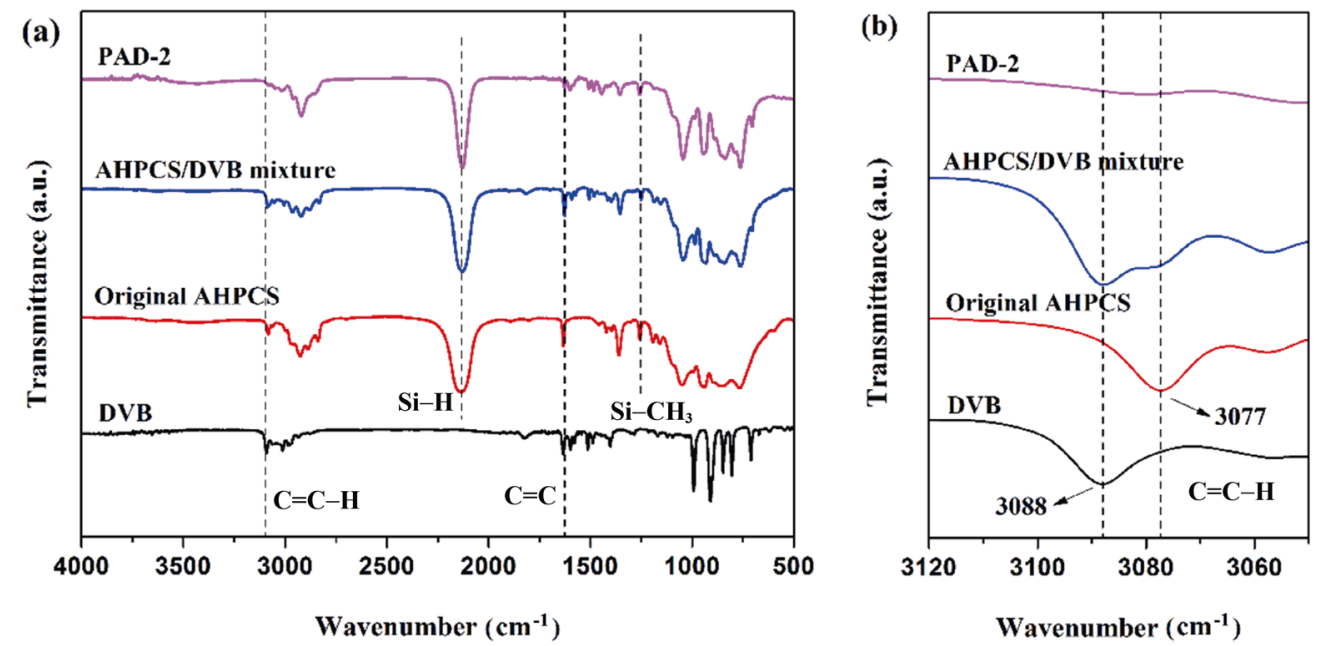

Fig. 2 FT-IR spectra of original AHPCS, DVB, unreacted AHPCS/DVB mixture, and single-source-precursor PAD-2.

the original AHPCS and obtained PAD. To make a comparison between the unreacted AHPCS/DVB mixture and resultant PDA-2, the absorption bands at 3088 (C-H stretch in $-\mathrm{CH}=\mathrm{CH}_{2}$ of DVB) and $3077 \mathrm{~cm}^{-1}$ (C-H stretch in $-\mathrm{CH}=\mathrm{CH}_{2}$ of AHPCS) nearly vanish, indicating that the $\mathrm{C}=\mathrm{C}$ groups from both the $\mathrm{DVB}$ and the AHPCS took part in chemical reactions. In our previous studies $[48,49]$, it was found that two major reactions can consume the $\mathrm{C}=\mathrm{C}$ bonds as follows: hydrosilylation $(\mathrm{Si}-\mathrm{H} / \mathrm{C}=\mathrm{C})$ and vinyl polymerization $(\mathrm{C}=\mathrm{C} / \mathrm{C}=\mathrm{C})$. The hydrosilylation reaction is fast even at low temperatures (it starts at $100-120{ }^{\circ} \mathrm{C}$ ) [28], whereas vinyl polymerizations start at higher temperatures (ca. $400{ }^{\circ} \mathrm{C}$ ) $[48,49]$. With such a low reaction temperature of $160{ }^{\circ} \mathrm{C}$, it is assumed that the hydrosilylation $(\mathrm{Si}-\mathrm{H} / \mathrm{C}=\mathrm{C})$ contributes to the consumption of $\mathrm{C}=\mathrm{C}$ groups of DVB. Besides, the intensity of the $\mathrm{Si}-\mathrm{H}$ bands (centered at $2100 \mathrm{~cm}^{-1}$ ) from the PAD-2 decreases compared with that of unreacted AHPCS/DVB mixture, which again confirms the occurrence of hydrosilylation $(\mathrm{Si}-\mathrm{H} / \mathrm{C}=\mathrm{C})$. The FT-IR results clearly show that the DVB was chemically bonded to the AHPCS chains to form the carbon-rich single-source-precursors.

Based on the FT-IR results, the reaction pathways and polymer chain morphologies during the synthesis of the single-source-precursor are demonstrated in Fig. 3. The hydrosilylation between the $\mathrm{C}=\mathrm{C}$ groups of DVB and the $\mathrm{Si}-\mathrm{H}$ groups of AHPCS, and the self-hydrosilations of AHPCS are involved to form the single-source-precursors.

\section{2 Composition and microstructure of ceramics}

Figure 4(a) shows the Raman spectra of the PAD-2 derived ceramics annealed at different temperatures. All spectra indicate the presence of both disorder-induced $\mathrm{D}$ and graphite-like $\mathrm{G}$ bands. The D-band at $1352 \mathrm{~cm}^{-1}$ corresponds to the presence of amorphous carbonaceous products, disordered carbon or defects in graphite, and the G-band at $1580 \mathrm{~cm}^{-1}$ is related to the signal from graphite [50]. Additionally, two bands at around 2690 and $2920 \mathrm{~cm}^{-1}$ are attributed to overtones or combination modes of the D- and G-bands [41]. With increasing annealing temperature, the D- and G- bands show smaller line width and the intensities of the G- and 2Dbands $\left(2700 \mathrm{~cm}^{-1}\right)$ grow gradually, indicating progressive structural ordering of the carbon. The Raman spectra of ceramics derived from different precursors annealed at the same temperature of $1600{ }^{\circ} \mathrm{C}$ were also measured and the results are shown in Fig. 4(b). The graphitization grade $\left(G_{\mathrm{G}}\right)$ of carbon-containing material can be calculated as follows: $I_{\mathrm{G}} /\left(I_{\mathrm{G}}+I_{\mathrm{D}}\right) \times 100 \%$, where $I_{\mathrm{G}}$ and $I_{\mathrm{D}}$ are the intensity of the G- and D-bands, respectively [50]. The $G_{\mathrm{G}}$ of $1600{ }^{\circ} \mathrm{C}$ ceramics derived from AHPCS-blank, PAD-1, PAD-2, and PAD-3 is $0.30,0.36,0.39$, and 0.40 , respectively, indicating that the ordering of carbon (degree of graphitization) is higher with the increase of free carbon of final ceramics.

Moreover, with the DVB content increasing, the carbon content of obtained ceramics significantly increases from $33.44 \mathrm{wt} \%$ to $59.66 \mathrm{wt} \%$ (Table 2). Correspondingly, the free carbon content increases from $6.62 \mathrm{wt} \%$ to $44.67 \mathrm{wt} \%$. The results indicate that as expected, the free carbon content of ceramics is significantly increased by the introduction of DVB.

The PAD-2 derived ceramics annealed at different temperatures were carefully studied by transmission 
(a)

AHPCS

DVB

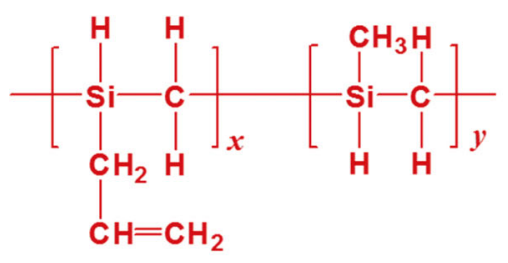

$\overbrace{6 \mathrm{~h}} \frac{160^{\circ} \mathrm{C}, \mathrm{Ar}}{6 \mathrm{~h}}$

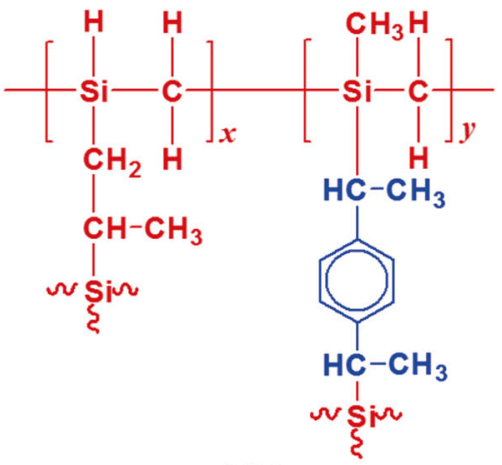

a-addition

$\mathrm{HC}=\mathrm{CH}_{2}$

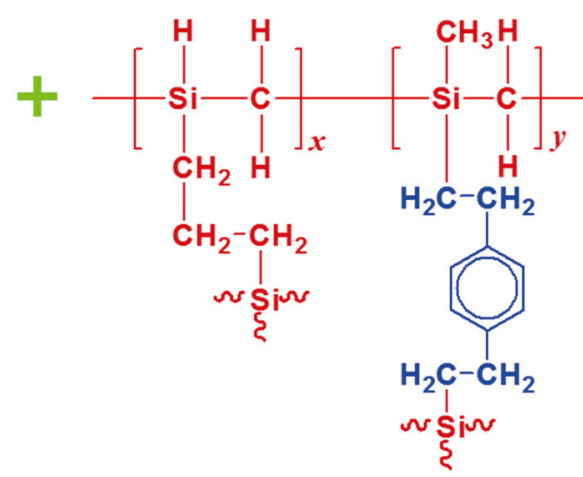

$\beta$-addition

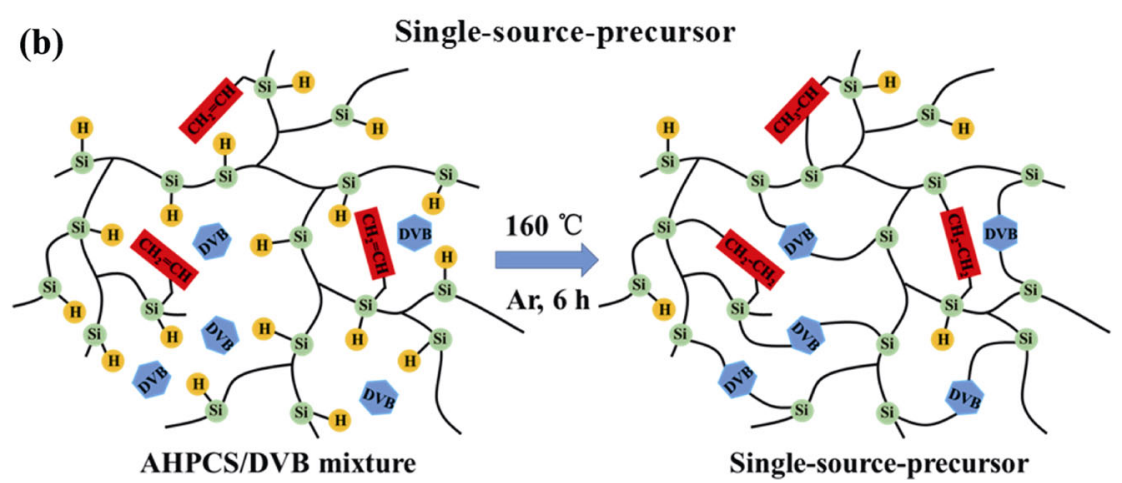

Fig. 3 (a) Reaction pathways and (b) polymer chain morphologies during the synthesis of the single-source-precursor.
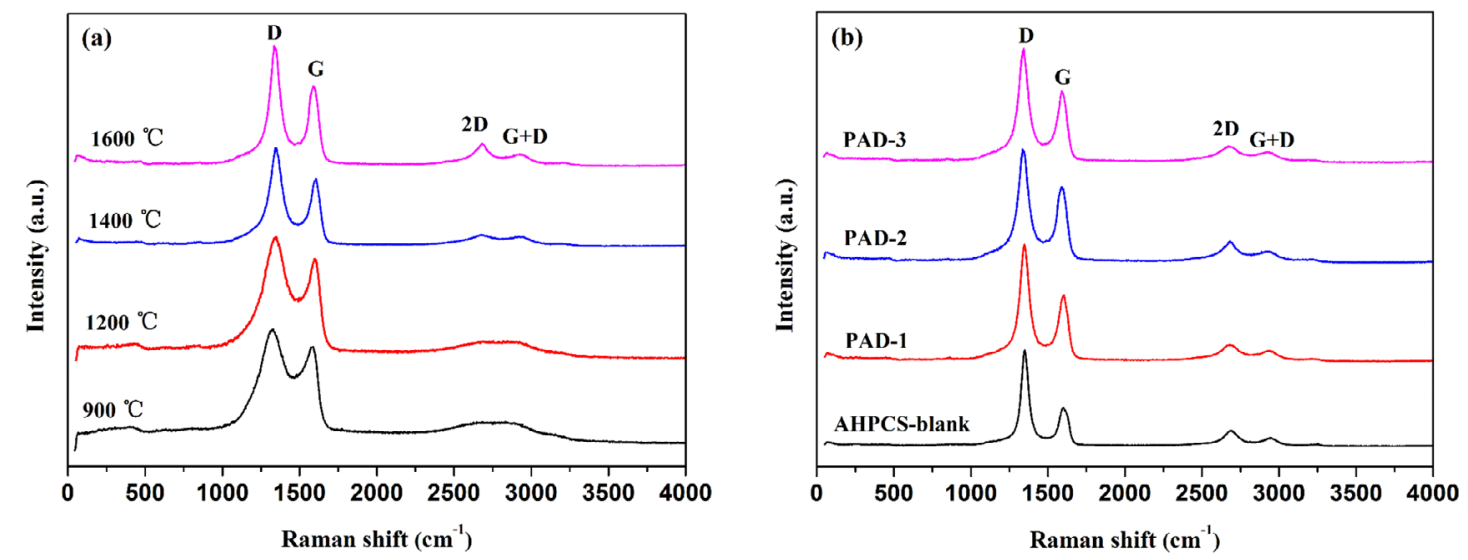

Fig. 4 Raman spectra of (a) PAD-2 derived ceramics annealed at different temperatures and (b) $1600{ }^{\circ} \mathrm{C}$ ceramics derived from different precursors.

electron microscopy (TEM) with respect to the evolution of its phase composition and microstructure (Fig. 5). The $900{ }^{\circ} \mathrm{C}$ sample shows no crystalline phases or segregated phase separation. The 1200 and $1400{ }^{\circ} \mathrm{C}$ samples show a gradually clear Debye ring rather than diffuse halo. High-resolution TEM (HRTEM) imaging shows the characteristic nanostructure of the ceramic where $\beta$-SiC crystallites and poorly organized turbostratic 
Table 2 Chemical composition of $1600{ }^{\circ} \mathrm{C}$ ceramics derived from different precursors

\begin{tabular}{|c|c|c|c|c|c|c|}
\hline \multirow{2}{*}{ Sample } & \multicolumn{3}{|c|}{ Chemical composition (wt $\%$ ) } & \multirow{2}{*}{ Empirical formula } & \multirow{2}{*}{ Mole fraction } & \multirow{2}{*}{ Free carbon $(w t \%)$} \\
\hline & $\mathrm{Si}^{\mathrm{d}}$ & $\mathrm{C}^{\mathrm{a}}$ & $\mathrm{O}^{\mathrm{b}}$ & & & \\
\hline AHPCS-blank-1600 & 64.44 & 33.44 & 2.12 & $\mathrm{SiC}_{1.21} \mathrm{O}_{0.06}$ & $0.97 \mathrm{SiC} \cdot 0.03 \mathrm{SiO}_{2} \cdot 0.24 \mathrm{C}$ & 6.62 \\
\hline PAD-1-1600 & 47.58 & 50.33 & 2.09 & $\mathrm{SiC}_{2.47} \mathrm{O}_{0.08}$ & $0.96 \mathrm{SiC} \cdot 0.04 \mathrm{SiO}_{2} \cdot 1.51 \mathrm{C}$ & 30.72 \\
\hline PAD-2-1600 & 41.14 & 56.25 & 2.61 & $\mathrm{SiC}_{3.19} \mathrm{O}_{0.11}$ & $0.94 \mathrm{SiC} \cdot 0.06 \mathrm{SiO}_{2} \cdot 2.25 \mathrm{C}$ & 39.60 \\
\hline PAD-3-1600 & 37.48 & 59.66 & 2.86 & $\mathrm{SiC}_{3.71} \mathrm{O}_{0.13}$ & $0.93 \mathrm{SiC} \cdot 0.07 \mathrm{SiO}_{2} \cdot 2.78 \mathrm{C}$ & 44.67 \\
\hline
\end{tabular}

${ }^{\mathrm{a}}$ Measured by Carbon/Sulfur Analyzer; ${ }^{\mathrm{b}}$ Measured by Oxygen/Nitrogen Analyzer; ${ }^{\mathrm{d}}$ Determined by the difference.
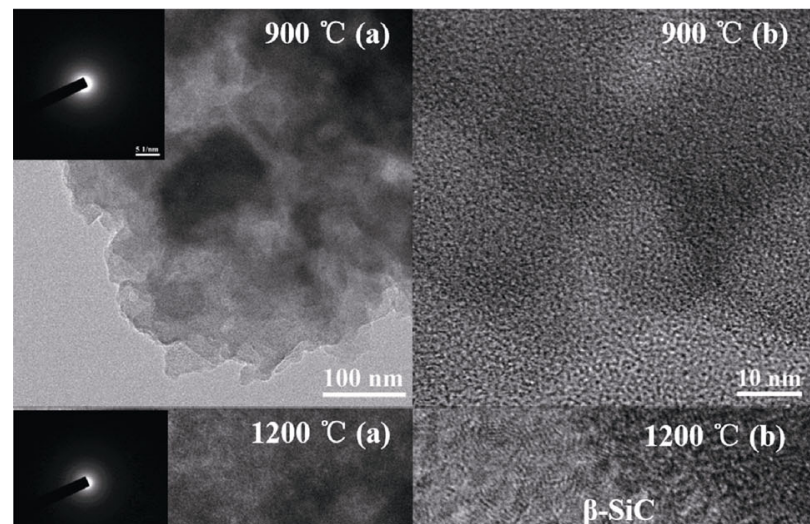

3

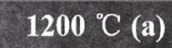

$1200^{\circ} \mathrm{C}(\mathrm{b})$
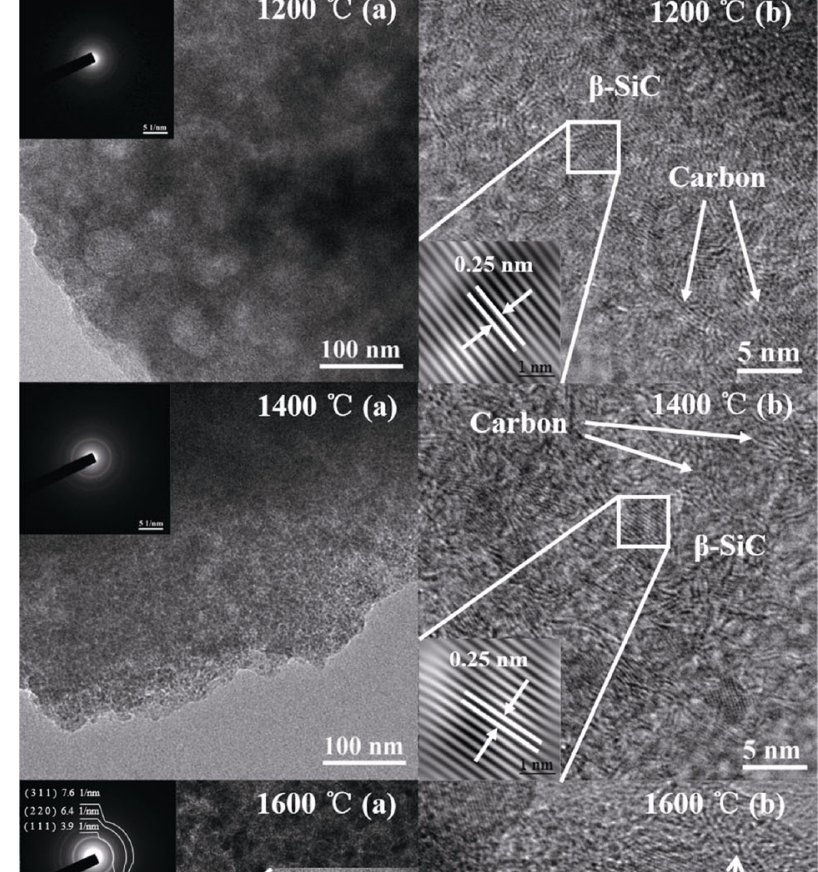

(a)
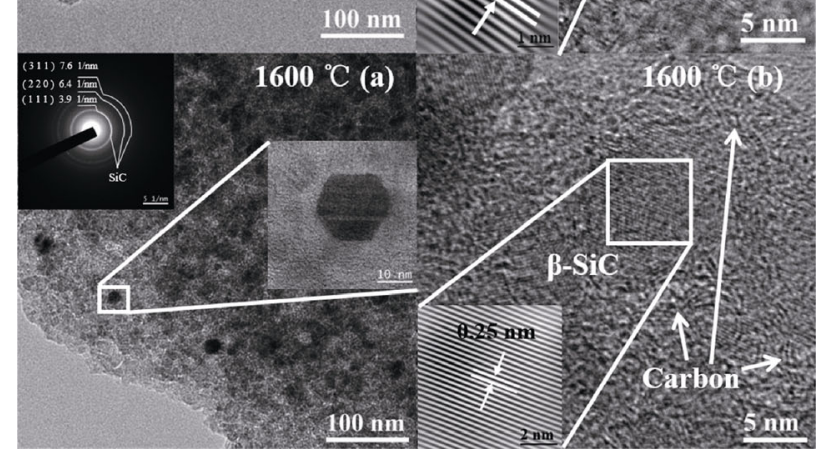

Fig. 5 (a) Bright field lattice images (insets: selected area electron diffraction) and (b) HRTEM images of PAD-2 derived ceramics annealed at different temperatures (insets: diffraction patterns obtained by Fourier filtered transformation). carbon are dispersed in an amorphous $\mathrm{SiC}(\mathrm{O})$ matrix. With increasing the annealing temperature, the obtained ceramic reveals an enhanced crystallization as shown in the selected area electron diffraction (SAED) insets. Even annealed at the highest temperature of $1600{ }^{\circ} \mathrm{C}$, the resultant ceramic is composed of superfine $\mathrm{SiC}$ nanocrystals with an average size of smaller than $20 \mathrm{~nm}$ and turbostratic carbon networks. On the basis of Raman spectroscopy and TEM results, the resultant carbon-rich $\mathrm{SiC}$ ceramics are characterized as a $\mathrm{SiC} / \mathrm{C}$ nanocomposite.

Based on the TEM observation, a scheme shown in Fig. 6 is used to demonstrate the microstructural evolution of resultant carbon-rich $\mathrm{SiC}$ ceramics. With the annealing temperature increasing, the carbon-rich SiC ceramics undergo phase separation, from amorphous to crystalline feature. Meanwhile, free carbon is segregated at $1200{ }^{\circ} \mathrm{C}$ and is better organized to form conductive networks with the temperature increasing. For PDCs, the amorphous phase acts as A phase (electrically insulating matrix), the turbostratic carbon and nanocrystalline $\mathrm{SiC}$ can be considered as the so-called B phase (electrically lossy phase) [9].

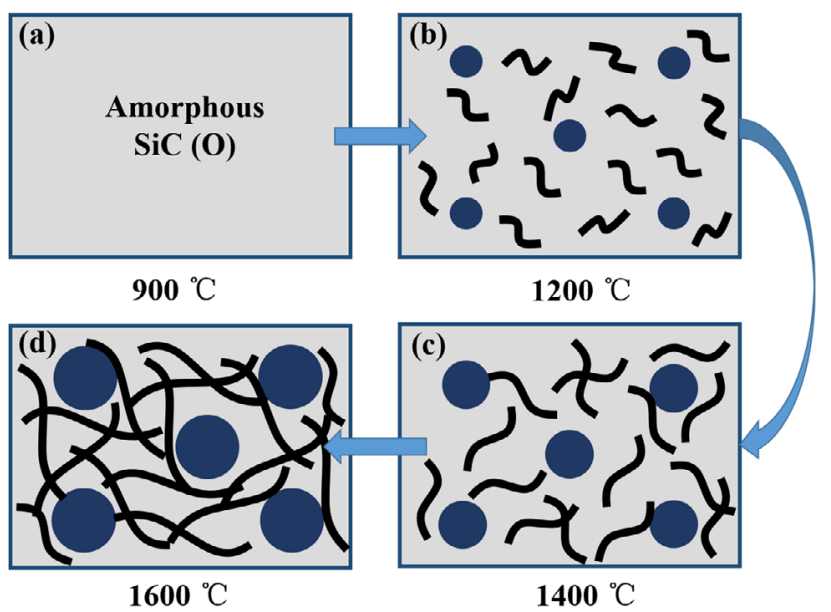

Fig. 6 Schematic illustration of the microstructural evolution of carbon-rich $\mathrm{SiC}$ ceramics. 
Therefore, the resultant carbon-rich $\mathrm{SiC}$ ceramics are expected to have superior EM absorption properties.

\section{3 Dielectric properties}

To determine the complex permittivity $\left(\varepsilon_{r}=\varepsilon^{\prime}-\mathrm{j} \varepsilon^{\prime \prime}\right)$ and dielectric $\operatorname{loss}\left(\tan \delta=\varepsilon^{\prime \prime} / \varepsilon^{\prime}\right)$ in $2-18 \mathrm{GHz}$ frequency range, a vector network analyzer was employed and the results are shown in Figs. 7 and 8. All samples were prepared by mixing the as-synthesized ceramic powders with paraffin wax. As shown in Fig. 7, the average $\varepsilon^{\prime}$ of PAD-2 derived ceramics annealed at 900, 1200, 1400, and $1600{ }^{\circ} \mathrm{C}$ amounts $3.93,9.01,9.21$, and 12.45,
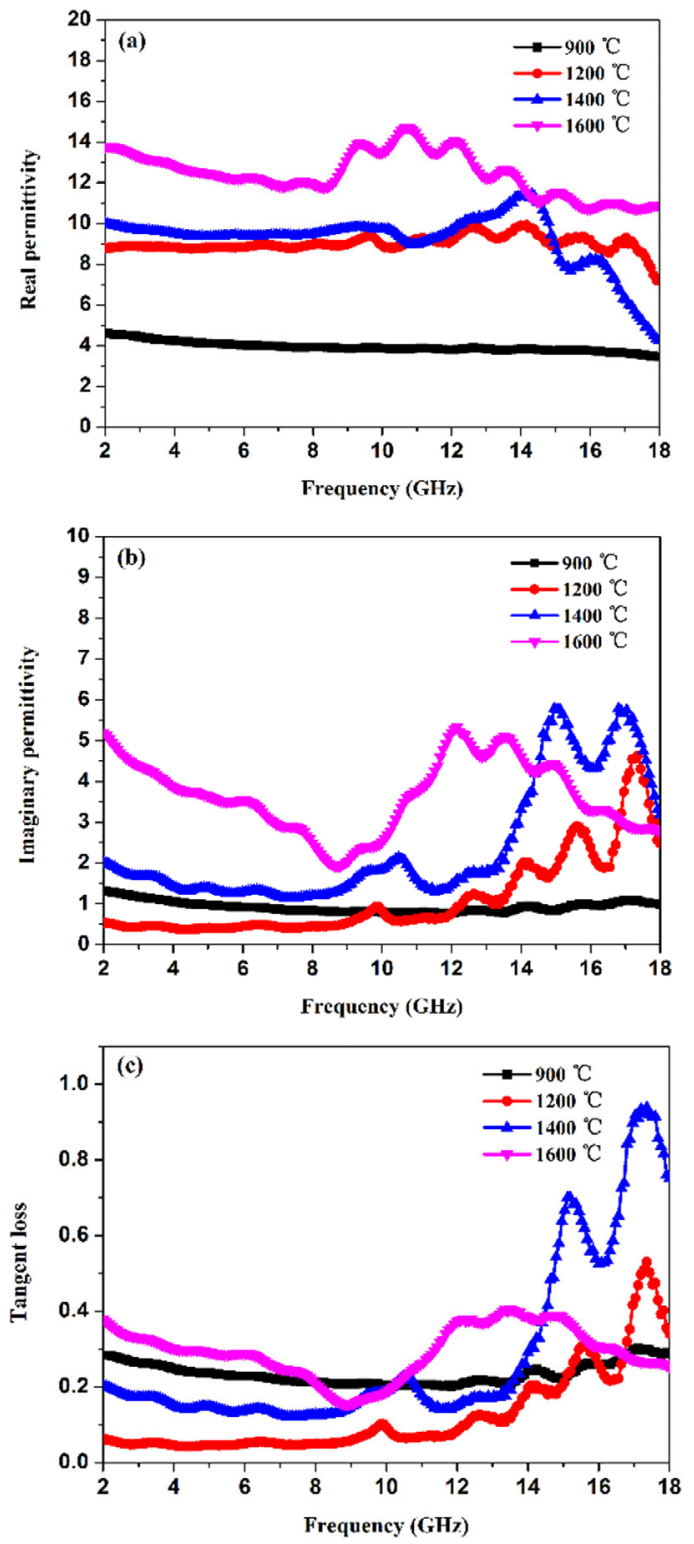

Fig. 7 (a) The real permittivity, (b) the imaginary permittivity, and (c) the dielectric loss of PAD-2 derived ceramics annealed at different temperatures.
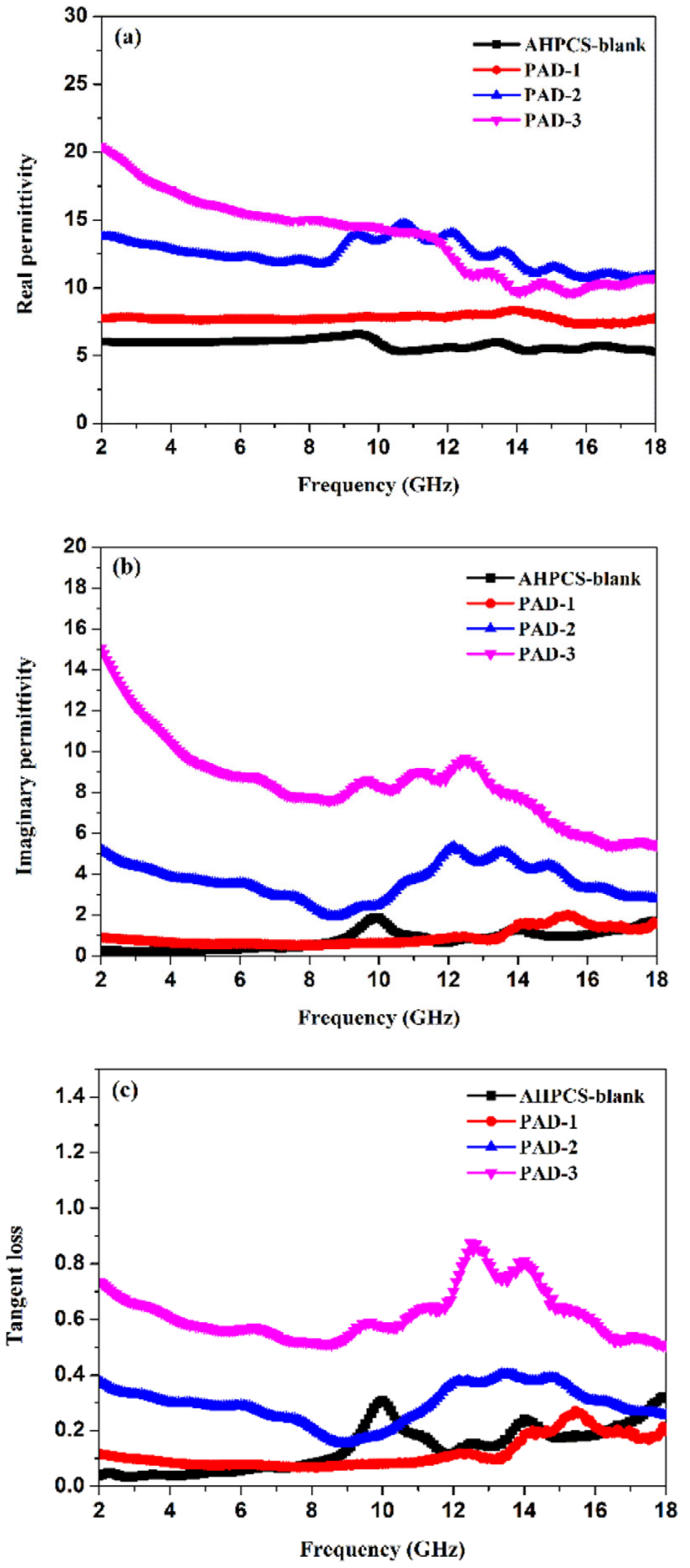

Fig. 8 (a) The real permittivity, (b) the imaginary permittivity, and (c) the dielectric loss of AHPCS-blank, PAD-1, PAD-2, and PAD-3 derived ceramics annealed at $1600{ }^{\circ} \mathrm{C}$.

respectively. The results indicate that the $\varepsilon^{\prime}$ increases with the annealing temperature increasing. According to the Debye theory, the $\varepsilon^{\prime}$ is related to the dipolar polarization and interfacial polarization of the electrons. As shown in Figs. 5 and 6, phase segregation occurs at $1200{ }^{\circ} \mathrm{C}$ to form $\beta$-SiC nanocrystallites and turbostratic carbon, which significantly increases polarization loss at the homo-interfaces and hetero-interfaces. As a result, the $\varepsilon^{\prime}$ dramatically increases from 900 to $1200{ }^{\circ} \mathrm{C}$ during the phase separation from amorphous to crystallization features. In general, the imaginary part $\varepsilon^{\prime \prime}$ is related to dielectric loss and a higher loss tangent 
$\tan \delta_{\varepsilon}$ implies higher attenuation ability under the condition of impedance match. With respect to the average $\varepsilon^{\prime \prime}$, it reaches $0.92,1.13,2.38$, and 3.65 corresponds to the ceramics annealed at 900, 1200, 1400 , and $1600{ }^{\circ} \mathrm{C}$, respectively. For the average $\tan \delta_{\varepsilon}$, it amounts $0.23,0.13,0.28$, and 0.29 , respectively. The results indicate that with the annealing temperature increasing, the $\varepsilon^{\prime \prime}$ gradually increases because the better organized free carbon (Figs. 7(a) and 8) can enhance the electrical conductivity of resultant ceramics.

The influence of free carbon content of $1600{ }^{\circ} \mathrm{C}$ ceramics on dielectric properties was also investigated and the results are displayed in Fig. 8. The average $\varepsilon^{\prime}$ of AHPCS-blank derived ceramic is 5.83, whereas that of PAD-1, PAD-2, and PAD-3 derived ceramics is 7.76, 12.45, and 13.76, respectively. With the DVB content increasing, the enhanced free carbon content of resulting ceramics (Table 2) can increase the polarization at interfaces including $\mathrm{C} / \mathrm{C}$ and $\mathrm{SiC} / \mathrm{C}$ interfaces, leading to the increasing of $\varepsilon^{\prime}$. On the other hand, the increased $\varepsilon^{\prime}$ should be attributed to electrical loss, because increasing free carbon content can enhance the conductivity. Besides, the average $\varepsilon^{\prime \prime}\left(\tan \delta_{\varepsilon}\right)$ of AHPCS-blank, PAD-1, PAD-2, and PAD-3 derived ceramics is $0.78(0.14), 0.91(0.12), 3.65(0.29)$, and 8.46 (0.62), respectively. As expected, the enhanced free carbon in final ceramics can form electrical conductive networks, leading to an increase of both $\varepsilon^{\prime \prime}$ and $\tan \delta_{\varepsilon}$. Especially, the average $\varepsilon^{\prime \prime}$ and $\tan \delta_{\varepsilon}$ of PAD-2 derived ceramic significantly increase compared with those of AHPCS and PAD-1, probably due to the percolation threshold.

\section{4 Electromagnetic absorption properties}

For EM wave absorption materials, reflection coeffcient $(R C)$ is used to characterize the absorption properties. Based on the transmission-line theory and the metal back-panel model, the $R C$ can be calculated from the relative complex permeability and permittivity [9]:

$$
\begin{aligned}
& R C(\mathrm{~dB})=20 \cdot \log _{10}\left|\frac{\left(Z_{\text {in }}-1\right)}{\left(Z_{\text {in }}+1\right)}\right| \\
& Z_{\text {in }}=\sqrt{\frac{\mu}{\varepsilon}} \tan h\left(\frac{\mathrm{j} 2 \pi \sqrt{\mu \varepsilon} f d}{c}\right)
\end{aligned}
$$

where $Z_{\text {in }}, d$, and $\mu$ are the normalized input impedance, thickness, and permeability of the material, respectively; $\tan h$ presents hyperbolic tangent function; $c$ is the light velocity in a vacuum; and $f$ is the microwave frequency.
Figures 9 and 10 show the theoretical $R C$ values of obtained ceramics. The frequency range corresponding to an $R C$ value $<-10 \mathrm{~dB}$ is defined as the effective absorption bandwidth $(E A B)$, which means that more than $90 \%$ of the EM waves can be attenuated. As shown in Fig. 9(a), the PAD-2 derived ceramics annealed at $900-1400{ }^{\circ} \mathrm{C}$ possess weak EM absorption capability with the $\mathrm{RC}$ higher than $-5 \mathrm{~dB}$. The $1600{ }^{\circ} \mathrm{C}$ ceramic exhibits the best absorption properties with a $R C_{\min }=$ $-35.3 \mathrm{~dB}$ at $15.20 \mathrm{GHz}$ (more than $99.9 \%$ EM waves can be attenuated), $d=1.50 \mathrm{~mm}$, and $E A B=4.48 \mathrm{GHz}$, due to the better ordering of free carbon with the annealing temperature increasing. The EM absorption performance of ceramics with different free carbon contents annealed at $1600{ }^{\circ} \mathrm{C}$ was calculated and the results are shown in Fig. 9(b). The ceramics derived from the AHPCS-blank and PAD-1 show weak EM absorption properties with the $R C$ values higher than $-3 \mathrm{~dB}$. For the PAD-2 and PAD-3 derived ceramics, they possess much lower $R C_{\text {min }}$ values with -35.3 and $-24.8 \mathrm{~dB}$, respectively, corresponding to much better EM absorption performance. The results show that
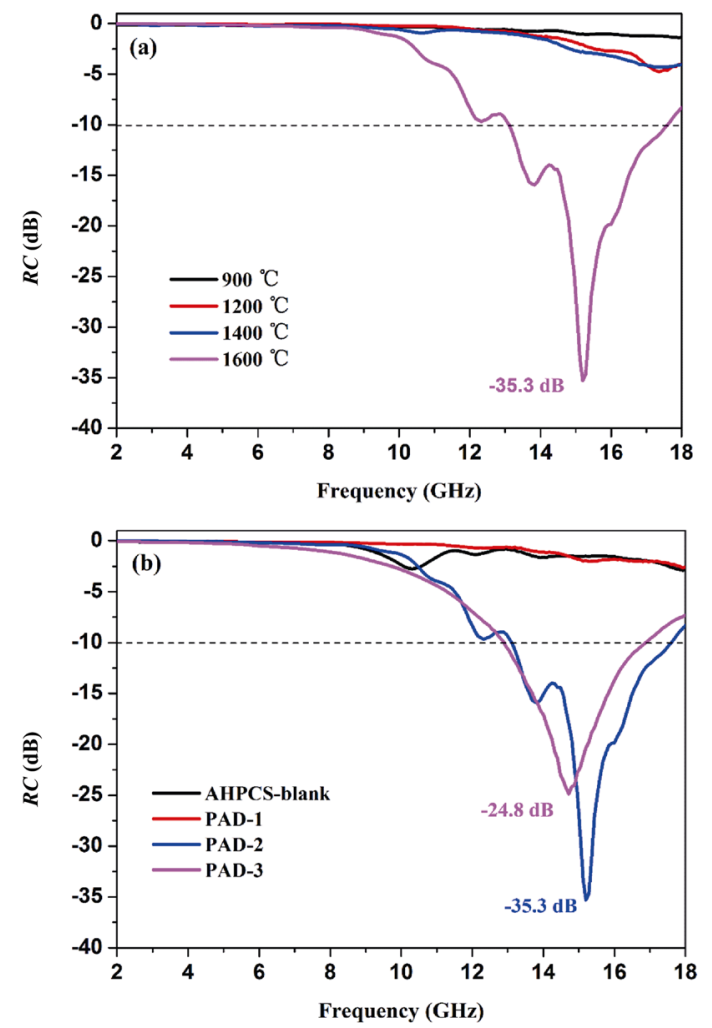

Fig. 9 Calculated theoretical $R C$ values of (a) PAD-2 derived ceramics annealed at different temperatures with a thickness of $1.50 \mathrm{~mm}$ and (b) AHPCS-blank, PAD-1, PAD-2, and PAD-3 derived ceramics annealed at $1600{ }^{\circ} \mathrm{C}$ with a thickness of $1.50 \mathrm{~mm}$. 

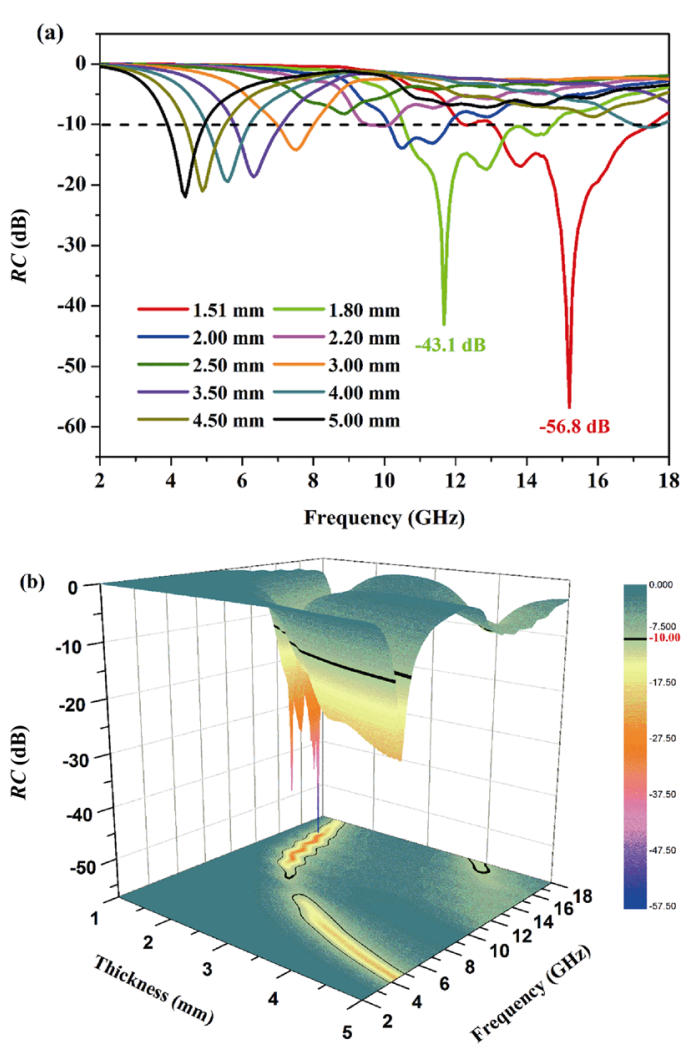

Fig. 10 (a) Calculated theoretical $R C$ values of composites of PAD-2 derived carbon-rich $\mathrm{SiC}$ mixed with wax versus frequency at different sample thickness variation and (b) corresponding 3D images.

with the increase of free carbon content, the EM absorption performance is significantly enhanced. Among all the samples, the PAD-2 derived ceramics show the best EM absorption properties with the lowest $R C_{\min }$.

The $R C$ of PAD-2 derived ceramic annealed at $1600{ }^{\circ} \mathrm{C}$ at different thicknesses were also calculated, as shown in Fig. 10.
It is worth mentioning that the $R C_{\min }$ reaches $-56.8 \mathrm{~dB}$ at $15.22 \mathrm{GHz}, d=1.51 \mathrm{~mm}$, and $E A B=$ $4.43 \mathrm{GHz}$, indicating that more than $99.999 \% \mathrm{EM}$ waves can be attenuated by the obtained carbon-rich $\mathrm{SiC} /$ paraffin wax composites. The results show that the present carbon-rich $\mathrm{SiC}$ ceramics have to be considered as promising EM wave absorbers which can be applied in harsh environments.

Table 3 summarizes EMA properties for various PDCs in references. In comparison to the previous studies, either the broadest $E A B$ of $4.48 \mathrm{GHz}$ or the ultra-small thickness in this study is excellent. The results indicate that the present carbon-rich $\mathrm{SiC}$ ceramics exhibit promising EM absorption performance among all the reported PDCs containing in-situ generated free-carbon.

The associated EM wave (EMW) absorption mechanisms based on the carbon-rich $\mathrm{SiC} /$ paraffin wax composites are proposed, as illustrated in Fig. 11. After

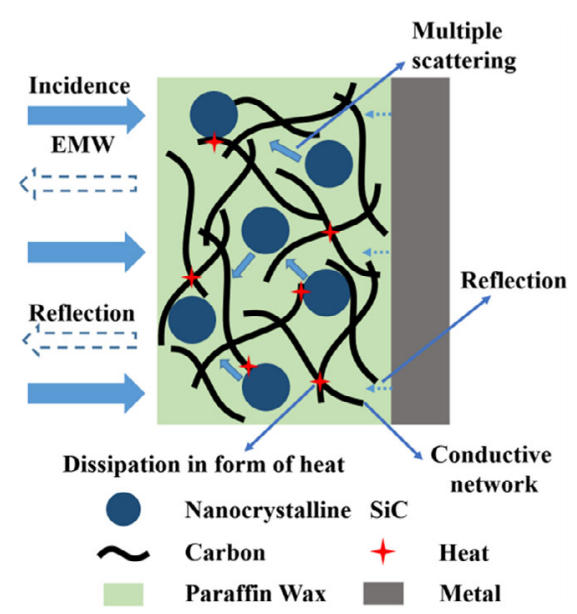

Fig. 11 Schematic illustration of EMW absorption for carbon-rich $\mathrm{SiC} /$ paraffin wax composites.

Table 3 Summary of EMW absorption properties for various PDCs containing in-situ formed free carbon in references

\begin{tabular}{|c|c|c|c|c|c|c|c|}
\hline \multirow{2}{*}{ Sample } & \multirow{2}{*}{ Composition } & \multirow{2}{*}{$\begin{array}{l}R C_{\text {min }} \\
(\mathrm{dB})\end{array}$} & \multicolumn{2}{|c|}{ Absorption bandwidth } & \multirow{2}{*}{ Matrix } & \multirow{2}{*}{$\begin{array}{c}\text { Per. } \\
(w t \%)\end{array}$} & \multirow{2}{*}{ Ref. } \\
\hline & & & $E A B(\mathrm{GHz})$ & Thickness (mm) & & & \\
\hline $\mathrm{SiC} / \mathrm{C}$ & $\mathrm{SiC}$, amorphous $\mathrm{SiC}$, free carbon & -56.8 & 4.48 & 1.51 & Paraffin & 40 & This study \\
\hline $\mathrm{SiCN}$ & $\begin{array}{l}\mathrm{SiC}, \mathrm{Si}_{3} \mathrm{~N}_{4} \text {, amorphous } \mathrm{SiCN}, \mathrm{CNWs}, \\
\text { graphene-like free carbon }\end{array}$ & -38.0 & 4.20 & $\begin{array}{l}4.50+3.00 \\
\text { (multilayer) }\end{array}$ & - & 100 & [32] \\
\hline $\mathrm{SiOC}$ & $\mathrm{SiC}, \mathrm{Fe}_{3} \mathrm{Si}$, amorphous $\mathrm{SiOC}$, free carbon & -46.0 & 3.50 & 2.93 & - & 100 & [33] \\
\hline $\mathrm{SiCN}$ & Amorphous $\mathrm{SiCN}$, free carbon & -12.5 & 10.0 & 8.00 & Paraffin & 33 & [34] \\
\hline SiCN NWs & $\mathrm{SiC}, \mathrm{Si}_{3} \mathrm{~N}_{4}$, amorphous $\mathrm{SiO}_{x} \mathrm{C}_{y}$ and $\mathrm{SiO}_{x} \mathrm{C}_{y} \mathrm{~N}_{z}$, free carbon & -53.1 & 5.60 & 1.95 & Paraffin & 35 & [35] \\
\hline $\mathrm{SiC} / \mathrm{C}$ & $\mathrm{SiC}$, amorphous $\mathrm{SiC}$, free carbon & -35.0 & 1.34 & 1.50 & Paraffin & 75 & [36] \\
\hline $\mathrm{SiCN}$ & Amorphous $\mathrm{SiCN}$, free carbon & -59.6 & 4.00 & 2.70 & - & 100 & [37] \\
\hline $\mathrm{Si}-\mathrm{C}-\mathrm{Co}(\mathrm{O})$ & $\mathrm{SiC}, \mathrm{CoSi}, \mathrm{Co}_{2} \mathrm{Si}$, amorphous $\mathrm{SiC}$, free carbon & -42.4 & 3.94 & 2.65 & Paraffin & 33 & [38] \\
\hline $\mathrm{SiBCN}$ & Amorphous $\mathrm{SiBCN}$, free carbon & -71.8 & 3.65 & 3.08 & - & 100 & [39] \\
\hline $\mathrm{SiC} / \mathrm{HfC}_{x} \mathrm{~N}_{1-x} / \mathrm{C}$ & $\mathrm{SiC}, \mathrm{HfC}_{x} \mathrm{~N}_{1-x}$, free carbon, amorphous SiHfCN & -47.0 & 3.10 & 2.40 & Paraffin & 40 & [41] \\
\hline
\end{tabular}


the phase separation, the hierarchical structures of $\mathrm{SiC}$ nanocrystals and turbostratic carbon induce lots of interfaces in the nanocomposites, which are of great benefit to the EMW absorption.

\section{Conclusions}

In summary, the carbon-rich $\mathrm{SiC}$ ceramics were obtained by a facile PDC approach, starting from the AHPCS and carbon-rich DVB. Using FT-IR, it is confirmed that the hydrosilation between $\mathrm{Si}-\mathrm{H}$ groups of AHPCS and $\mathrm{C}=\mathrm{C}$ bonds of $\mathrm{DVB}$ occurs to form a carbon-rich single-source precursor. Compared to the AHPCS-derived ceramic, the free carbon contents of single-sourceprecursor derived $\mathrm{SiC}$ ceramics annealed at $1600{ }^{\circ} \mathrm{C}$ are tailorable and significantly enhanced from $6.62 \mathrm{wt} \%$ to $44.67 \mathrm{wt} \%$. After annealing at the temperature range of $1200-1600{ }^{\circ} \mathrm{C}$, the obtained carbon-rich $\mathrm{SiC}$ ceramics are composed of superfine $\mathrm{SiC}$ nanocrystals and turbostratic carbon networks dispersed in an amorphous $\mathrm{SiC}(\mathrm{O})$ matrix. The dielectric properties and EM absorption performance of resultant carbon-rich $\mathrm{SiC}$ ceramics are significantly improved by the better ordering and higher free carbon contents. For the $1600{ }^{\circ} \mathrm{C}$ ceramics derived from the PAD-2, the $R C_{\min }$ reaches $-56.8 \mathrm{~dB}$ at $15.2 \mathrm{GHz}$ with a thickness of $1.51 \mathrm{~mm}$ and a relatively broad $E A B$ of $4.43 \mathrm{GHz}$, indicating the excellent EM absorption performance. The present carbon-rich $\mathrm{SiC}$ ceramics open a facile strategy to fabricate excellent EMW absorbers applied in harsh environments.

\section{Acknowledgements}

This study was supported by the National Natural Science Foundation of China (No. 51872246) and Shenzhen Science and Technology Projects (JCYJ20180306172957494).

\section{References}

[1] Ye XL, Chen ZF, Ai SF, et al. Porous SiC/melamine-derived carbon foam frameworks with excellent electromagnetic wave absorbing capacity. $J$ Adv Ceram 2019, 8: 479-488.

[2] Li XL, Yin XW, Han MK, et al. $\mathrm{Ti}_{3} \mathrm{C}_{2} \mathrm{MXenes} \mathrm{modified}$ with in situ grown carbon nanotubes for enhanced electromagnetic wave absorption properties. J Mater Chem C 2017, 5: 4068-4074.

[3] Han MK, Yin XW, Li XL, et al. Laminated and two-dimensional carbon-supported microwave absorbers derived from MXenes. ACS Appl Mater Interfaces 2017, 9: 20038-20045.

[4] Xu HL, Yin XW, Zhu M, et al. Carbon hollow microspheres with a designable mesoporous shell for high-performance electromagnetic wave absorption. ACS Appl Mater Interfaces 2017, 9: 6332-6341.

[5] Li XL, Yin XW, Xu HL, et al. Ultralight MXene-coated, interconnected SiCnws three-dimensional lamellar foams for efficient microwave absorption in the X-band. ACS Appl Mater Interfaces 2018, 10: 34524-34533.

[6] Kong L, Wang C, Yin XW, et al. Electromagnetic wave absorption properties of a carbon nanotube modified by a tetrapyridinoporphyrazine interface layer. J Mater Chem C 2017, 5: 7479-7488.

[7] Li XL, Yin XW, Han MK, et al. A controllable heterogeneous structure and electromagnetic wave absorption properties of $\mathrm{Ti}_{2} \mathrm{CT}_{x}$ MXene. J Mater Chem C 2017, 5: 7621-7628.

[8] Yin XW, Kong L, Zhang LT, et al. Electromagnetic properties of $\mathrm{Si}-\mathrm{C}-\mathrm{N}$ based ceramics and composites. Int Mater Rev 2014, 59: 326-355.

[9] Duan WY, Yin XW, Li Q, et al. A review of absorption properties in silicon-based polymer derived ceramics. J Eur Ceram Soc 2016, 36: 3681-3689.

[10] Li Q, Yin XW, Duan WY, et al. Electrical, dielectric and microwave-absorption properties of polymer derived $\mathrm{SiC}$ ceramics in X band. J Alloys Compd 2013, 565: 66-72.

[11] Duan WY, Yin XW, Li Q, et al. Synthesis and microwave absorption properties of $\mathrm{SiC}$ nanowires reinforced $\mathrm{SiOC}$ ceramic. J Eur Ceram Soc 2014, 34: 257-266.

[12] Li Q, Yin XW, Feng LY. Dielectric properties of $\mathrm{Si}_{3} \mathrm{~N}_{4}-\mathrm{SiCN}$ composite ceramics in X-band. Ceram Int 2012, 38: 6015-6020.

[13] Ye F, Zhang LT, Yin XW, et al. Dielectric and EMW absorbing properties of PDCs-SiBCN annealed at different temperatures. J Eur Ceram Soc 2013, 33: 1469-1477.

[14] Duan WY, Yin XW, Ye F, et al. Synthesis and EMW absorbing properties of nano SiC modified PDC-SiOC. $J$ Mater Chem C 2016, 4: 5962-5969.

[15] Ding DH, Zhou WC, Zhou X, et al. Influence of pyrolysis temperature on structure and dielectric properties of polycarbosilane derived silicon carbide ceramic. Trans Nonferrous Met Soc China 2012, 22: 2726-2729.

[16] Ye F, Zhang LT, Yin XW, et al. Dielectric and microwaveabsorption properties of $\mathrm{SiC}$ nanoparticle/SiBCN composite ceramics. J Eur Ceram Soc 2014, 34: 205-215.

[17] Ye F, Zhang LT, Yin XW, et al. Dielectric and EMW absorbing properties of PDCs-SiBCN annealed at different temperatures. J Eur Ceram Soc 2013, 33: 1469-1477.

[18] Liu XM, Xu HL, Xie FT, et al. Light-weight and highly flexible $\mathrm{TaC}$ modified $\mathrm{PyC}$ fiber fabrics derived from 
cotton fiber textile with excellent electromagnetic shielding effectiveness. Chem Eng J 2020, 387: 124085.

[19] Fan XM, Yuan RZ, Li X, et al. RGO-supported core-shell $\mathrm{SiO}_{2} @ \mathrm{SiO}_{2} /$ carbon microsphere with adjustable microwave absorption properties. Ceram Int 2020, 46: 14985-14993.

[20] Ren FY, Yin XW, Mo R, et al. Hierarchical carbon nanowires network modified PDCs-SiCN with improved microwave absorption performance. Ceram Int 2019, 45 : 14238-14248.

[21] Zhang YJ, Yin XW, Ye F, et al. Effects of multi-walled carbon nanotubes on the crystallization behavior of PDCs-SiBCN and their improved dielectric and EM absorbing properties. J Eur Ceram Soc 2014, 34: 1053-1061.

[22] Liu XM, Yu ZJ, Ishikawa R, et al. Single-source-precursor synthesis and electromagnetic properties of novel RGO-SiCN ceramic nanocomposites. $J$ Mater Chem C 2017, 5: 7950-7960.

[23] Liu XM, Yu ZJ, Chen LQ, et al. Role of single-sourceprecursor structure on microstructure and electromagnetic properties of CNTs-SiCN nanocomposites. J Am Ceram Soc 2017, 100: 4649-4660.

[24] Luo CJ, Jiao T, Gu JW, et al. Graphene shield by SiBCN ceramic: A promising high-temperature electromagnetic wave-absorbing material with oxidation resistance. ACS Appl Mater Interfaces 2018, 10: 39307-39318.

[25] Han MK, Yin XW, Duan WY, et al. Hierarchical graphene/SiC nanowire networks in polymer-derived ceramics with enhanced electromagnetic wave absorbing capability. J Eur Ceram Soc 2016, 36: 2695-2703.

[26] Wang XF, Mera G, Morita K, et al. Synthesis of polymerderived graphene/silicon nitride-based nanocomposites with tunable dielectric properties. J Ceram Soc Japan 2016, 124: 981-988.

[27] Colombo P, Mera G, Riedel R, et al. Polymer-derived ceramics: 40 years of research and innovation in advanced ceramics. J Am Ceram Soc 2010: no.

[28] Ionescu E, Kleebe HJ, Riedel R. Silicon-containing polymer-derived ceramic nanocomposites (PDC-NCs): Preparative approaches and properties. Chem Soc Rev 2012, 41: 5032.

[29] Stabler C, Ionescu E, Graczyk-Zajac M, et al. Silicon oxycarbide glasses and glass-ceramics: "All-Rounder" materials for advanced structural and functional applications. J Am Ceram Soc 2018, 101: 4817-4856.

[30] Wen QB, Yu ZJ, Riedel R. The fate and role of in situ formed carbon in polymer-derived ceramics. Prog Mater Sci 2020, 109: 100623.

[31] Cordelair J, Greil P. Electrical conductivity measurements as a microprobe for structure transitions in polysiloxane derived Si-O-C ceramics. J Eur Ceram Soc 2000, 20:
1947-1957.

[32] Li Q, Yin XW, Duan WY, et al. Improved dielectric properties of PDCs-SiCN by in situ fabricated nano-structured carbons. J Eur Ceram Soc 2017, 37: 1243-1251.

[33] Duan WY, Yin XW, Luo CJ, et al. Microwave-absorption properties of SiOC ceramics derived from novel hyperbranched ferrocene-containing polysiloxane. $J$ Eur Ceram Soc 2017, 37: 2021-2030.

[34] Guo X, Feng YR, Lin X, et al. The dielectric and microwave absorption properties of polymer-derived $\mathrm{SiCN}$ ceramics. J Eur Ceram Soc 2018, 38: 1327-1333.

[35] Wang P, Cheng LF, Zhang LT. Lightweight, flexible SiCN ceramic nanowires applied as effective microwave absorbers in high frequency. Chem Eng J 2018, 338: 248-260.

[36] Wang YC, Xiao P, Zhou W, et al. Microstructures, dielectric response and microwave absorption properties of polycarbosilane derived $\mathrm{SiC}$ powders. Ceram Int 2018, 44: 3606-3613.

[37] Song Y, He LH, Zhang XF, et al. Highly efficient electromagnetic wave absorbing metal-free and carbon-rich ceramics derived from hyperbranched polycarbosilazanes. J Phys Chem C 2017, 121: 24774-24785.

[38] Luo CJ, Duan WY, Yin XW, et al. Microwave-absorbing polymer-derived ceramics from cobalt-coordinated poly(dimethylsilylene)diacetylenes. J Phys Chem C 2016, 120: 18721-18732.

[39] Luo CJ, Tang YS, Jiao T, et al. High-temperature stable and metal-free electromagnetic wave-absorbing $\mathrm{SiBCN}$ ceramics derived from carbon-rich hyperbranched polyborosilazanes. ACS Appl Mater Interfaces 2018, 10: 28051-28061.

[40] Yu ZJ, Min H, Zhan JY, et al. Preparation and dielectric properties of polymer-derived SiCTi ceramics. Ceram Int 2013, 39: 3999-4007.

[41] Wen QB, Feng Y, Yu ZJ, et al. Microwave absorption of $\mathrm{SiC} / \mathrm{HfC}_{x} \mathrm{~N}_{1-x} / \mathrm{C}$ ceramic nanocomposites with $\operatorname{HfC}_{x} \mathrm{~N}_{1-x}-$ carbon core-shell particles. J Am Ceram Soc 2016, 99: 2655-2663.

[42] Widgeon S, Mera G, Gao Y, et al. Effect of precursor on speciation and nanostructure of SiBCN polymer-derived ceramics. J Am Ceram Soc 2013, 96: 1651-1659.

[43] Kaspar J, Graczyk-Zajac M, Choudhury S, et al. Impact of the electrical conductivity on the lithium capacity of polymer-derived silicon oxycarbide (SiOC) ceramics. Electrochimica Acta 2016, 216: 196-202.

[44] Feng Y, Yu ZJ, Riedel R. Enhanced hydrogen evolution reaction catalyzed by carbon-rich $\mathrm{Mo}_{4.8} \mathrm{Si}_{3} \mathrm{C}_{0.6} / \mathrm{C} / \mathrm{SiC}$ nanocomposites via a PDC approach. J Am Ceram Soc 2020, 103: 1385-1395.

[45] Huang MH, Fang YH, Li R, et al. Synthesis and properties of liquid polycarbosilanes with hyperbranched structures. $J$ Appl Polym Sci 2009, 113: 1611-1618. 
[46] Zhou MH, Kim SH, Park JG, et al. Preparation and oil-absorptivity of crosslinked polymers containing stearylmethacrylate, 4-t-butylstyrene, and divinylbenzene. Polym Bull 2000, 44: 17-24.

[47] Yu ZJ, Zhan JY, Huang MH, et al. Preparation of a hyperbranched polycarbosilane precursor to $\mathrm{SiC}$ ceramics following an efficient room-temperature cross-linking process. J Mater Sci 2010, 45: 6151-6158.

[48] Li HB, Zhang LT, Cheng LF, et al. Polymer-ceramic conversion of a highly branched liquid polycarbosilane for SiC-based ceramics. J Mater Sci 2008, 43: 2806-2811.

[49] Li HB, Zhang LT, Cheng LF, et al. Effect of the polycarbosilane structure on its final ceramic yield. $J$ Eur Ceram Soc 2008, 28: 887-891.

[50] Ionescu E, Francis A, Riedel R. Dispersion assessment and studies on AC percolative conductivity in polymer-derived
Si-C-N/CNT ceramic nanocomposites. J Mater Sci 2009, 44: 2055-2062.

Open Access This article is licensed under a Creative Commons Attribution 4.0 International License, which permits use, sharing, adaptation, distribution and reproduction in any medium or format, as long as you give appropriate credit to the original author(s) and the source, provide a link to the Creative Commons licence, and indicate if changes were made.

The images or other third party material in this article are included in the article's Creative Commons licence, unless indicated otherwise in a credit line to the material. If material is not included in the article's Creative Commons licence and your intended use is not permitted by statutory regulation or exceeds the permitted use, you will need to obtain permission directly from the copyright holder.

To view a copy of this licence, visit http://creativecommons. org/licenses/by/4.0/. 